\title{
Epidemiological situation of leprosy in Salvador from 2001 to $2009^{*}$
}

\author{
Shirlei Cristina Moreira ${ }^{1}$
}

\author{
Claudilson José de Carvalho Batos ${ }^{2}$
}

Lara Tawil ${ }^{3}$

\begin{abstract}
Mycobacterium leprae was first described as the bacillus that causes leprosy, a chronic granulomatous infectious disease, in 1873 by Amauer Hansen. Leprosy is part of a group of 10 neglected diseases and Bahia has endemic levels of this illness, varying between high and very high. The detection of 52 new cases of leprosy in children under 15 years old in Salvador in 2006 is alarming, and suggests an early contact with the disease. The aim of this review is to analyze the epidemiological situation, the detection rate and evaluate the clinical and epidemiological profile of leprosy in Salvador, in the period 2001-2009. A retrospective cross-sectional study was performed using secondary data collected at Notifiable Diseases Information System Database (SINAN) through the notification of patients with leprosy. Over these nine years 3,226 patients were reported, with a predominance of: females $(51.5 \%)$, and clinical multibacillary forms in the general population $(51.7 \%)$, but when we analyze those under 15 years old, paucibacillary forms (tuberculoid + indeterminate) prevailed. The tuberculoid form was the most diagnosed type of presentation. The annual detection rate in Salvador remained at a very high level of endemicity during the studied period and for those under 15 years old it ranged between high and very high. Grade 2 disabilities both at the time of diagnosis and at discharge after cure, varied between low and medium. Based on these data we conclude that the high levels of leprosy detection rates in the general population, plus the variation between high and very high levels in those under 15 years old, associated with the medium level of grade 2 disabilities at the time of diagnosis and discharge, demonstrate the need for improvement on the existing services, investment in active case finding and training of the healthcare professionals in Salvador.
\end{abstract}

Keywords: Endemic diseases; Epidemiology; Leprosy

\section{INTRODUCTION}

Mycobacterium leprae is the transmitter bacillus of leprosy, an infectious neuro-dermatological disease that is part of the so-called neglected diseases, along with Chagas disease, schistosomiasis, tuberculosis, dengue fever, malaria and leishmaniasis, among others $^{-1}$ It is known that $1 / 6$ of the world population is infected with one of these diseases, making them epidemiologically relevant, and thus led to the creation of a program called the National Health Research Priorities Agenda (NHRPA) that has invested R\$ 39 million since 2003 when it was started, $\mathrm{R} \$ 2.5$ million of which were allocated for leprosy. ${ }^{1}$

Brazil has one of the largest annual detection rates when compared to other countries. Among the Brazilian states, those located in the North and Northeast Regions are the ones from which most of the cases recorded at the Notifiable Diseases Information System Database (SINAN) comes; among them is the state of Bahia, which has high levels of endemicity. $2,3,4$

The most commonly cited risk factors for the disease dissemination are crowding, low family income, lack of sewage, malnutrition, and low literacy rates, but the main determinant is the genetic factor. ${ }^{5-9}$

Amauer Hansen was the first to describe this bacillus. It has a slow cellular division, low pathogenicity and a high ability to infect. Transmission occurs most frequently through the upper airways mucosa by multibacillary treatment-naïve carriers. The incubation period is variable and can take up to 30 years; for this reason leprosy was formerly considered a disease of adults. Currently, with the notification of the disease in children under 15 years it

Received on 03.10.2012.

Approved by the Advisory Board and accepted for publication on 22.03.2013.

Work performed on the Notifiable Diseases Information System Database - Ministry of Health (SINAN) - Salvador (BA), Brazil.

Conflict of interest: None

Financial Support: None

MD, Dermatologist - Physician at the Ministry of Health and at Santa Izabel Hospital - Salvador (BA), Brazil

MD, Specialist in infectious Diseases at Couto Maia Hospital - Professor at the Science and Technology College - Salvador (BA), Brazil

MD - Private practice - Salvador (BA), Brazil

(C2013 by Anais Brasileiros de Dermatologia 
appears that the contact is happening earlier. ${ }^{7,10}$

Leprosy manifestations are variable and depend on the type of individual immune response against the bacilli (Th1 or Th2); considered bipolar (high-resistance poles - tuberculoid and low-resistance poles- lepromatous; plus two variants, one low-resistance - borderline and another indeterminate, which can be high or low- resistance), these clusters also differ in the number of visible cutaneous lesions, thus classifying the patient into paucibacillary or multibacillary which will determine the type of treatment. ${ }^{11,12}$

Leprosy diagnosis is achieved through clinical signs of cutaneous lesions, sensibility loss and nerve thickening. Tests such as bacilloscopy, histopathology, Mitsuda reaction, ML flow (IgM) dosage and skin or nerve biopsy are used when there is doubt in the diagnosis and also to assess the patient's prognosis. ${ }^{13-15}$

Polychemotherapy (the use of several drugs to treat a disease) is currently the treatment that is offered free-of-charge to the population and that has great efficacy. Nevertheless, there are low adherence rates because of the adverse events that range from alteration of skin color in the affected locations, hemolytic anemia, erythroderma, exfoliative dermatitis, and dapsone and flu-like syndromes to bone marrow aplasia. ${ }^{16,17}$

It is important to highlight the psychological disorders suffered by leprosy patients, varying from social isolation to attempt suicide (8 cases in Brazil). ${ }^{18,19}$

In addition to the patient, contacts must also be assessed and reported, so that the progression of the disease can be restrained through BCG vaccine prophylaxis, that should be offered to every household member whether or not they present a scar from previous vaccination. ${ }^{7,14}$

These elements show the importance of studying leprosy, training professionals and investing in this area. This study is intended to alert healthcare personnel to this public health issue, already eradicated in developed countries and considered a neglected endemy in Brazil. The relevance of this study is justified by the lack of recent data in the medical literature about leprosy in the city of Salvador.

\section{THEORETICAL BASIS HISTORY}

Leprosy is considered one of the oldest diseases in history; there are biblical accounts that depict the disease formerly known by its Greek name lepra. Since that time, lepers were considered unclean, punished by God and should be openly segregated so that others did not come near them. There were also reports of isolation in specific locations and the only cure deemed possible was by a miracle. ${ }^{20,21}$

Even several years A.D. many conventions did not change and with the firmly established stigma and the lack of knowledge about treatment, prejudice and fear when faced with a leprosy patient remained present while the sick continued to be isolated in homes removed from the city center. ${ }^{20}$

In 1873, the leprosy bacillus was described by Norwegian physician Amauer Hansen, hence the current name of the disease. The name however, was altered in several countries between the 70's and 80's in order to reduce the prejudice against patients, after the development of research, advances in medicine and drug discoveries; by then Hansen's disease came to be considered a milder illness, curable, preventable and with minimal sequelae., ${ }^{722}$

With the technological revolution in large cities and the migratory flow towards urban centers, cities expanded in a haphazard fashion, accumulating large populations in disproportionately small spaces with low sanitary standards, thus leading to the spread of various infectious diseases, including Hansen's disease, which since then is considered an epidemic.,23,24,25

\section{DEFINITION AND MICROBIOLOGY}

Leprosy is a protracted infectious disease, caused by Mycobacterium leprae, primarily transmitted through contact with patients of the lepromatous or borderline type, which have not yet been diagnosed or started treatment. These individuals have a high bacillary load and may cause interpersonal transmission. ${ }^{5,24,26}$ Transmission can occur through skin lesions, which are an entryway for infection, but they develop mainly through the upper airways. There are reports of contamination by bodily fluids such as milk, semen, sweat and vaginal secretions, but these do not have epidemiological significance. ${ }^{7}$ The primary area of contamination is the home - having current cases of Hansen in the family increases by 2.9 times the chance of contracting the disease. ${ }^{5}$

Mycobacterium leprae is essentially an intracellular bacillus, straight or partially curved, which is seen histopathologically in cluster arrangements, characteristic of this parasite. It is alcohol acid-resistant and displays tropism for Schwann cells and for the skin. Although it has low pathogenicity levels, it is highly infectious and in cases where there is no resistance, it may infect other organs such as lymph nodes, eyes, testicles and liver. ${ }^{11}$

The average incubation period is five years, two to five on the tuberculoid form and eight to twelve years in lepromatous cases; this variance is due to the bacillus' slow binary division (12 to 21 days), and to the immune response (mediated cellular and humoral immunity) and genetic factors of the patient. ${ }^{11,24}$

Leprosy is considered an urban endemy by its presence over time in a given region and because the city is where most reported cases are concentrated, although 
recent studies demonstrate its anthropozoonotic character (animals such as armadillos, monkeys and chimpanzees serve as reservoirs for the bacilli) and its preference for tropical climates, which explains the difficulty in eradicating the disease in Brazil.

\section{IMMUNOLOGY}

The patient may present two types of immune response after the infection: Th1 or Th2 reaction. Th1 response is based on cellular immunity, with a predominance of T-lymphocytes that produce increased levels of IL-2 and INF-y; it is effective against the bacillus, and causes minor skin involvement, considering for practical purposes up to five cutaneous lesions or the so called paucibacillary form. ${ }^{11,14,25}$

The other reaction, Th2, promotes induction of IL-4, IL-5 and IL-10 that are ineffective against Mycobacterium leprae, generating a more severe, specific skin infiltration, thus when more than five cutaneous lesions are seen, the case is considered multibacillary. ${ }^{11,14}$

Because of this variation in the immune response, leprosy is considered a polymorphic disease presenting two stable and opposite poles (lepromatous and tuberculoid) and two variant or unstable forms (indeterminate and borderline).

The standard measure of cell-mediated immunity is the Mitsuda test, performed with an intradermal injection of inactive bacilli, its response is measured after three to four weeks by detecting or not an induration at the site of application. The test is positive when it promotes a delayed hypersensitivity reaction that generates an induration. If this is not seen, it means the test is negative and indicates that the host cannot effectively eliminate the bacillus and has a tendency to develop a disseminated form of the disease. ${ }^{11}$

\section{CLASSIFICATION}

Two types of classification are used, the clinical and the operational (practical) one: The operational classification will define the treatment; it takes into consideration the quantity of skin lesions. Up to 5 lesions and the disease is classified as paucibacillary and above it, as multibacillary. Positive bacilloscopy however classifies the case as multibacillary, regardless of the number of lesions. ${ }^{14}$

The other classification used in the diagnosis of hanseniasis is the clinical form categorization. In Brazil, for research purposes, we use the classification described by Ridley and Jopling (1966) because it evaluates host resistance and histopathology, although its use by healthcare services would be difficult (tuberculoid, borderline, subdivided into borderline-tuberculoid, borderline-borderline and borderline-lepromatous; subpolar lepromatous and lepromatous); and we also use the classification formulated in the VI International
Leprology Congress (Madrid, 1953). In this paper we used the Madrid classification recommended by the World Health Organization (WHO), which classifies the disease into indeterminate (I), tuberculoid (T), dimorphic (D) and lepromatous or Virchowian (V) based on the characteristics of the lesions. . $^{1215,27}$

\section{DIAGNOSIS}

The diagnosis of leprosy is given when one or more of the following features are found: a) cutaneous lesions with abnormal or diminish sensibility, b) peripheral nerves affliction with or without thickening of the nervous trunk, c) positive intradermal bacilloscopy (scale of 0 to $6+$ ). Other complementary tests such as histopathology, Mitsuda reaction, serum IgM dosage and skin or nerve biopsy are indicated in cases of diagnostic uncertainty. ${ }^{7}$

The diseases that can mimic leprosy's clinical presentation and must be considered as differential diagnosis are pityriasis versicolor, vitiligo, sarcoidosis, secondary or tertiary syphilis, peripheral diabetic neuropathies, rheumatoid arthritis, among others. ${ }^{7,13}$

\section{PSYCHOLOGICAL ASPECTS}

A study performed in 1995 in Brazil, with 500,000 leprosy patients showed that these individuals were mostly in their productive years, and many psychological issues linked to this fact were raised, such as the influence of the disease in work, family life and social integration. . $^{1726}$

In this study, male and female reactions were analyzed in separate and the authors concluded that women tended to rely greatly on religion after contracting the disease and also that they felt deprived of the stereotypical feminine roles (caring for children, cleaning the house) and consequently feared being abandoned by their husbands. Men, on the other hand, perceived the disease as a threat, an element that affected their sexual masculinity and their role as family providers; a disease that made them rethink their lives. On both genders there was great concern about physical appearance, and both reported avoiding social situations and circumstances that required explanations about the change in skin texture or pigmentation. ${ }^{17,19}$

\section{TREATMENT AND PROPHYLAXIS}

The standard treatment (multidrug therapy or MDT) was globally established in the early 80 's and in Brazil during 1990. With the spread of treatment from 1991 on, there was a reduction on prevalence rates supported by the increasing number of cured cases. ${ }^{28}$ Since then, polychemotherapy has been widely proved by several studies reporting high cure rate, and it is among the recommendations of the WHO Expert Committee, made in 1997 in Geneva as a strat- 
egy for eradication of leprosy. ${ }^{6}$

The new therapeutic regimen that reduced treatment time from ten to one year consists of using rifampicin and dapsone for six months for paucibacillary forms (tuberculoid and indeterminate), and using both drugs for 12 months with the addition of clofazimine in multibacillary forms (lepromatous and borderline). ${ }^{28}$

Patients should be regularly monitored for the appearance of neural lesions, and if confirmed, early treatment with corticosteroids should be instituted; the recovery rate being approximately $60 \%{ }^{29}$

The treatment has high efficacy rates, is offered free-of charge and does not require hospital admission; even so, multidrug therapy still finds opposition amongst the patients and had a dropout rate of $25 \%$ in $1994 . .^{16,17}$

Rifampicin belongs to the pharmacologic group of antituberculosis drugs and also acts as a potent bactericidal against Mycobacterium leprae, preventing by competition the formation of messenger RNA and forming a stable complex between the drug and bacterial RNA-polymerase. It was observed that 3 to 24 days after the use of this drug, bacilli were inactive in the skin and after 4 days in the nasal mucosa. ${ }^{30}$

Clofazimine also acts competitively with RNA and DNA preventing the formation of new bacteria. It causes the skin, urine and sweat to change their color to red, since these are its elimination routes. ${ }^{30}$

Dapsone is a sulfone that acts as a bacteriostatic competitively inhibiting the formation of RNA and bacterial DNA and the emergence of bacterial resistance to drugs, besides stimulating the phagocytic activity of polymorphonuclear leukocytes. ${ }^{30,31}$

Among the factors reported as determinants of non-adherence are the doctor-patient relationship, the lack of bonding between them, the patients' feeling of powerlessness regarding their health, lack of education (the latter influencing the failure to understand the orientation given by healthcare professionals), having to attend the clinic every 28 days to receive a supervised dose of treatment and also the major adverse events such as hemolytic anemia, druginduced hepatitis, exfoliative dermatitis and thrombocytopenia that usually occur in the first month of treatment. ${ }^{17,16}$ A study performed in São Paulo investigated alternatives to prevent the high dropout rate, and found that on days when healthcare professionals did not attend work the patient would not come either or would rather postpone the consultation; it also found that to see the patient even if he was not previously scheduled and whenever possible send a health worker to the patient's home to remind him to take the medication (the patient is deemed faulty after 15 days of the last monthly supervised dose) are factors that can improve adherence to treatment. ${ }^{17,25}$

An aspect to be considered regarding leprosy is the infectious profile within household contacts, a situation for which prophylaxis is available by BCG vaccination that protects against the most aggressive forms of the disease. ${ }^{14}$ There is evidence on the use of dapsone as chemoprophylaxis for these contacts in order to reduce the incidence of hanseniasis. ${ }^{29}$

\section{EPIDEMIOLOGY}

Brazil is an endemic country for leprosy along with 5 other countries that have not yet achieved the goal of eradicating the disease in 2005. In 2003 Brazil had the second highest number of cases worldwide. In 2006, the Ministry of Health announced a reduction of $24 \%$ in the detection rate between 2004 and 2005.,26

In 2006 WHO recorded 219,826 new cases in the world, and the countries with the most detected cases were Brazil, India, Madagascar, Myanmar, Nepal, Tanzania and Mozambique. ${ }^{24}$

Global data collected in 1997 in endemic places such as Pacific, Asia, Africa and Latin America, demonstrated that the only location showing an increase trend in detection rates over the last 20 years was Latin America; a fact that has been validated since then..$^{32}$ In the Americas $94 \%$ of cases are known; all of the new ones have been recorded in Brazil. ${ }^{7}$

Studies performed in 2001 in underprivileged continents such as Africa and Southeast Asia found rates of $11 \%$ and $18 \%$, respectively, of children younger than 15 years diagnosed with leprosy. In endemic areas, despite being a disease with a long incubation period, early contact of the child with the bacillus causes leprosy to develop in children between three to five years; a fact that added to poor sanitation conditions and the inadequacy of epidemiological surveillance and control, is considered a public health issue and exerts social, physical and psychological tolls in the pediatric population. ${ }^{10}$

In Brazil, between 1998 and 2005, the prevalence rate was reduced from a level considered average $(4.93 / 10,000$ in 1998) to a low level $(1.48 / 10,000$ in 2005), when 38,410 cases were recorded; the detection rate however remained very high during these years. ${ }^{27,32}$

The reduction on the prevalence rate can be attributed to improved sanitary conditions, public education about the disease and mainly to the treatment including dapsone; even so the numbers are still alarming. ${ }^{33}$

According to the Epidemiological Surveillance of the Ministry of Health $(\mathrm{MH})$, the North and Northeast regions stand out from the other areas, as the ones with the highest incidence rates of leprosy in Brazil. In 2005 the Northeast of Brazil, had a prevalence rate of 5.6 per 10,000 inhabitants (medium), while in the Southeast, that same year the index was 0.70 (low), indicating an irregular disease behavior 
nationwide. ${ }^{24,33}$ According to the rates recommended by the MH, Brazil's levels on endemy vary from hyperendemic (northern region), very high (north and center), high (southeast) and medium (south). These variations within the same country are explained by migration and unstructured growth. Thus, the combination of high population density and precarious sanitation contributes to higher rates on the less favored regions of Brazil. ${ }^{10}$

In an agreement made in 1991 during the $44^{\text {th }}$ World Conference of Health, Brazil had committed to eliminating Hansen's disease by the year 2000. In 1999, during the $3^{\text {rd }}$ Regional Conference PAHO / WHO on leprosy elimination in the Americas held in Venezuela, Brazil signed the Declaration of Caracas, pledging to eliminate leprosy as a public health issue by $2005 .^{10}$

The National Leprosy Elimination Program, in 2005, planned to strengthen the strategies for eliminating the disease, but despite the reduction, the objective was not achieved and the detection rate of leprosy in children under 15 years in Brazil was 0.60/10,000, considered too high by the WHO classification. ${ }^{27}$

The Leprosy Control Program of the State of Bahia Health Department (Sesab) reported that by the end of 2007 in Bahia, there was a prevalence rate of 2.5 per group of 10,000 inhabitants, a rate considered of medium endemicity by WHO parameters, while the detection of new cases remained in endemic levels, between high and very high. ${ }^{34}$

Data from the public healthcare system (Datasus), in the metropolitan region of Salvador in 2006, recorded 52 new cases of leprosy in children younger than 15 years. There is a consensus in the literature that the diagnosis of leprosy in patients younger than fifteen years can be routinely used as an indicator of the level of transmission and severity of the endemy. ${ }^{10,35}$

Based on these data, the epidemiological surveillance department in Brazil made a commitment with the World Health Organization to eliminate the disease by 2010 (reaching the rate of less than one patient per 100,000 inhabitants), through decentralization and actions financed by the SUS (Unified Healthcare System). This eradication, as a public health issue, would reduce the financial burden of leprosy to society and to health services. ${ }^{8,3,33}$

The strategy for eliminating leprosy led to significant reductions in the prevalence rate, but it did not affect the detection rate in most endemic countries. The reduction in prevalence rate is explained by operational changes in surveillance and treatment effectiveness, thus reducing the time a patient stays in SINAN database. However, the detection rate does not suffer the same variations, it is impacted by the continued transmission of Mycobacterium leprae and by actions to control the disease. Therefore, to analyze the epidemiological situation it is better to use the detection rate and not the prevalence rate. ${ }^{3,28}$

In a publication in January 2002, the International Leprosy Association stated that there was a dramatic reduction in the number of reported cases, although there were still concerns that even reaching a pre-defined prevalence level, leprosy would not disappear naturally; the irregularity and abandonment of treatment and the possibility of recurrence were cited among the main obstacles. ${ }^{29}$

The present study aims to assess the epidemiological situation of hanseniasis, detection rate and clinical and epidemiological profiles of leprosy patients in the city of Salvador, during the period of 2001 to 2009, using data from the Notifiable Diseases Information System Database - SINAN.

\section{OBJECTIVES}

\section{GENERAL OBJECTIVE}

The general objective was to analyze the epidemiological situation of leprosy in Salvador, in the period of 2001-2009.

\section{SPECIFIC OBJECTIVE}

The specific objective was to evaluate the detection rate of leprosy and the clinical and epidemiological profiles of patients with leprosy.

\section{RATIONALE}

In an agreement made with WHO, Brazil pledged to eliminate leprosy by the end of 2010, i.e., reduce the detection rate to less than one patient per 100,000 inhabitants. Studies indicate that the detection rate of leprosy has declined in the country, however unevenly. Given that in other states of the Northeast this indicator has remained high, the following questions were proposed. ${ }^{8,25,35}$ What was the annual detection rates in Salvador in recent years? Is the early detection occurring? What is the profile of the notified patient?

Thus, this study aims to analyze the epidemiological situation, the detection rate and the clinical and epidemiological profile of leprosy in Salvador, in the period of 2001-2009.

\section{METHODS}

\section{AREA AND STUDY POPULATION}

Brazil is a developing country, with a land area of $8,511,965 \mathrm{~km}^{2}$ and a population of over 140 million people, distributed among the 27 states and 5,565 municipalities. It is located primarily in the intertropical region and therefore has a great variety of climate with a predominance of hot and humid weather, diverse vegetation and topography, and a high hydric potential with one of the largest fresh water reserves in the world. ${ }^{36}$ 
The Brazilian Northeast is a region of semi-arid climate that has nine states and high poverty levels compared to other regions. Bahia is the biggest state of the region, with a population estimated in 2009 of 14,637,364 inhabitants and 417 municipalities. Among these, 115 are considered priorities for leprosy control, since they concentrate $97 \%$ of the cases detected in $2008 .{ }^{23,34}$

The city of Salvador, capital of Bahia, is the third most populous city in the country, with three million inhabitants living in an area of $706,799 \mathrm{~km}^{2}$. To serve the population in a fairly manner, the area was divided into 12 health districts, that have as a state reference for leprosy care the Specialized Hospital Dom Rodrigo de Menezes (HEDRM), located in the district Cajazeiras. ${ }^{34,37}$

\section{METHODOLOGICAL DESIGN}

A retrospective cross-sectional study was performed based on secondary data collected at SINAN (Notifiable Diseases Information System Database) to identify the detection rate and clinical profile of leprosy in Salvador, between 2001 and 2009.

\section{INCLUSION CRITERIA}

Patients with leprosy in the city of Salvador, reported to SINAN in the period of 2001-2009 were included in this study.

The diagnosis was essentially clinical and epidemiological achieved by analyzing the patient's past history, living conditions and his dermato-neurological examination. ${ }^{14}$

\section{EXCLUSION CRITERIA}

Patients not recorded in SINAN and/or without a diagnosis of leprosy were excluded from this study.

\section{RECRUITING AND SAMPLING PROCEDURES}

This study was performed with data collected at SINAN to identify the detection rate and the clinical and epidemiological profile of leprosy in Salvador, between 2001 and 2009.

\section{STUDY VARIABLES AND ANALYSIS METHOD}

The following variables were used:

- New cases diagnosed from 2001 to 2009.

- Sex.

- Age (total population and those under 15 years of age).

- Degree of physical disability:

- Grade 0 - No eyes, hands or feet problems secondary to leprosy.

- Grade 1 - Decrease or loss of sensibility in the eyes, hands and / or feet;

- Grade 2 - Disability or deformity in the eyes, hands and/or feet assessed at the time of diagnosis. ${ }^{14}$
- Operational classification

- Multibacillary (when there are more than five characteristic cutaneous lesions during the initial assessment)

- Paucibacillary (less than five skin lesions at baseline)

- Clinical form according to the Madrid classification

- Indeterminate (I) - One or few skin lesions, usually hypopigmented with decrease or loss of sensibility; may involve small cutaneous nerve branches. It is considered an early stage of the disease that can progress or evolve to cure. It is usually found in children and the bacilloscopy is negative.

- Tuberculoid (T) - A few well-defined, numbed, asymmetrical cutaneous lesions, smaller than $10 \mathrm{~cm}$, that may present as plaques or macules on dry and hairless skin. Bacilloscopy is negative and the Mitsuda test is positive, indicating an effective immune response.

- Dimorphic (D) - It has varied clinical and laboratory presentations, with numerous skin lesions which may appear similar to lepromatous leprosy, tuberculoid leprosy or both, and a bacilloscopy that may be positive or negative - when similar to the tuberculoid form.

- Lepromatous or Virchowian (V) - macular lesions mainly in the face and limbs, dry, with thinning hair and a wrinkled aspect. The leonine face (destroyed facial extremities, rough shaping of the nose and ears and madarosis loss of eyelashes and eyebrows) is characteristic, as well as, functional impairments by affected vascular innervation and nerve trunks. As the disease progresses, other organs are involved, especially the respiratory tract. Due to the high bacillary load, bacilloscopy is positive, while the Mitsuda test is negative because of the anergic immune response. ${ }^{13,7}$

\section{STATISTICAL ANALYSIS}

Collected data were tabulated with Microsoft Excel software in order to generate the graphics and tables with the results of this study.

Estimatives were based on the indicators proposed by Ordinance $\mathrm{N}^{\mathrm{O}} \cdot 125$ / svs-sas of March 26, 2009 that specified the actions to control leprosy, among them the monitoring of rates (annual detection rate for new cases and those under 15 years) and assessment of information that reflect the strength of morbidity, the magnitude and epidemiology of hanseniasis (proportion of leprosy cases with grade 2 disability at the time of diagnosis and at discharge) (Table 1): 
1. The annual detection rate of new leprosy cases is calculated by dividing the new cases residing in a specific area, diagnosed during that year, by the total population residing in the same area, during the same period, multiplied by 100,000 . The parameters are: hyperendemic: > 40.00/100,000 inhabitants. Very High: 20.00 to $39.99 / 100,000$ inhabitants. High: 10.00 to $19.99 / 100,000$ inhabitants. Medium: 2.00 to $9.99 / 100,000$ inhabitants. Low: $<2.00 / 100,000$ inhabitants.

2. The coefficient of annual detection of new cases of leprosy in children under 15 years of age is calculated by dividing the number of new cases in this specific population living in a determined area and diagnosed during that year, by the healthy population aged 0 to 14 , living in the same place and during the same period and multiplied by 100,000 . The parameters are: hyperendemic: >10,00/100,000 inhabitants. Very High: 5.00 to $9.99 / 100,000$ inhabitants. High: 2.50 to $4.99 / 100,000$ inhabitants. Middle: 0.50 to $2.49 / 100,000$ inhabitants. Low: $<0.50 / 100,000$ inhabitants.

3 . The proportion of leprosy cases with grade 2 disabilities at the time of diagnosis is calculated by dividing the number of new cases detected in that year with grade 2 disability by new cases with any degree of disability, multiplied by 100 . The parameters are: High:> 10\%, Medium: 5 to $9.9 \%$ and Low: $<5 \%$.

\section{ETHYCAL ASPECTS}

The Ethics Committee of Hospital Couto Maia approved the study on November 28, 2009 in the city of Salvador. Only after approval by the aforementioned Committee was the study initiated

\section{RESULTS}

From 2001 to 2009 a total of 3,226 patients were reported to SINAN in Salvador (Table 2).

The age distribution analysis showed a higher concentration of patients older than 15 years, 2,936 notifications (91\%).

The prevalence by gender evaluation observed the predominance of female patients (51.5\%), except in 2003 and 2008, in which male patients were the majority, $52.7 \%$ and $52.6 \%$, respectively (Table 2 ).

Considering the classification established by the Congress in Madrid there was a predominance of the tuberculoid form in $32.2 \%$ of cases, followed by dimorphic $(28.8 \%)$, lepromatous $(17.5 \%)$ and indeterminate forms (16.9\%) (Table 2).

The total number of paucibacillary cases (127 patients) was discordant with the addition of indeterminate (30) to tuberculoid cases (96), probably due to errors in classification or registration. (Table 2)

In the general population the paucibacillary form was predominant, 51.7\% (Graphic 1). Observing the absolute number of cases in the popula- tion, it is noticeable that there was an increase by 2004 and a significant decrease thereafter with a tendency to stabilize. Meanwhile detection rates remained at high levels of endemicity (Graphics 1 and 2).

The health districts that reported the most cases were Subúrbio Ferroviário (Railway Suburbs), Itapua, São Caetano/Valeria, Cabula/Beiru and Cajazeiras. (Graphic 3).

When comparing the first and last year of the sample, it is clear that there was an increase in the number of detections in these health districts except in Sao Caetano/Valeria (Graphics 4 and 5).

Two hundred and ninety cases were reported in the population under 15 years old, 9\% (Table 2).

The values varied during the study, but a decrease was observed in recent years. The annual detection rate varied between high and very high from 2003 to 2007, and was medium in 2009 (Graphic 6).

Paucibacillary was the predominant form 65.7\% (Graphic 7).

In the population aged 0 to 14 years, the districts with the highest numbers of notification were the same as in adult population analysis (Graphic 8).

Three thousand and twenty six of the 3,226 patients were examined (93\%) and 535 (17.6\%) presented some degree of disability. The proportion of cases with grade 2 disabilities was low in the period from 2001 to 2006, since then the percentage has increased, and the level passed to medium from 2007 to 2009 (Table 3).

\section{DISCUSSION}

The findings in the present study characterized the city of Salvador as an endemic area for leprosy. The detection rate of leprosy in the period of 2001 to 2009 remained at high levels of endemicity. Moreover, the coefficient in children under 15 years reached a very high level, indicating a possible expansion of the disease and an intense transmission.

The increase in the detection rate at the beginning of the study period (2001 to 2002) was due to a public policy aimed at a more effective form of notification. At that time, an active search for cases of leprosy was initiated by health districts with the help of the FHP (Family Health Program) while training programs in the identification of hanseniasis for the healthcare professionals were implemented, as observed by Ferreira. ${ }^{10}$

The variations observed were cause mainly by the profile of the administration at the time and also by the change in programs used by SINAN to store information (while changing from Windows to Sinannet, some data was lost), these drops in the numbers are seen in 2003 and 2007. ${ }^{3}$

In 2004 there was an increase in the detection 
TABLE 1: Indicators proposed by Ordinance no. 125/svs-sas of March 26, 2009 that specifies the actions for leprosy control.

\section{Annual detection rate for new cases of leprosy: \\ New cases in residents of Salvador diagnosed during the year total resident population $X 100,000$ \\ Hyperendemic: $\geq 40.00$ / 100,000 inhabitants. Very High: 20.00 to 39.99 / 100,000 inhabitants. \\ High: 10.00 to 19.99 / 100,000 inhabitants. \\ Medium: 2.00 to 9.99 / 100,000 inhabitants. Low: $<2.00$ / 100,000 inhabitants.}

2. Annual detection rate for new cases of leprosy in children under 15 years of age:

New cases in children under 15 years residing in Salvador diagnosed during the year population aged 0 to 14 years $\times 100,000$

Hyperendemic: $\geq 10.00$ / 100,000 inhabitants. Very High: 5.00 to 9.99 / 100,000 inhabitants.

High: 2.50 to 4.99 / 100,000 inhabitants. Medium: 0.50 to 2.49 / 100,000 inhabitants.

Low: $<0.50$ / 100,000 inhabitants.

\section{Proportion of leprosy cases with grade 2 disabilities at the} time of diagnosis:

Number of new cases with grade 2 disabilities diagnosed during the year

New cases with some degree of disability X 100

High: $\geq 10 \%$

Medium: 5 to $9.9 \%$

Low: $<5 \%$

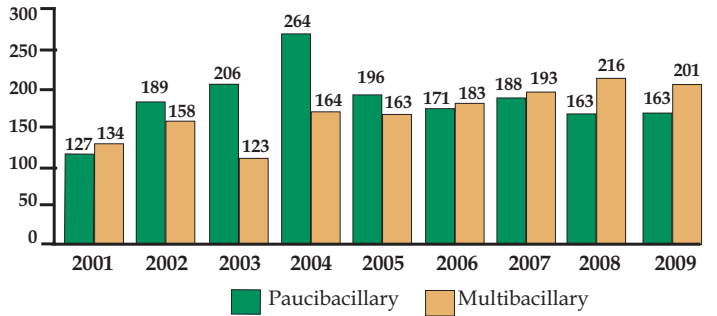

GraPH 1: Number of ACL cases treated at the Clinics Hospital, State University of Londrina, municipality of Londrina, 1998-2009

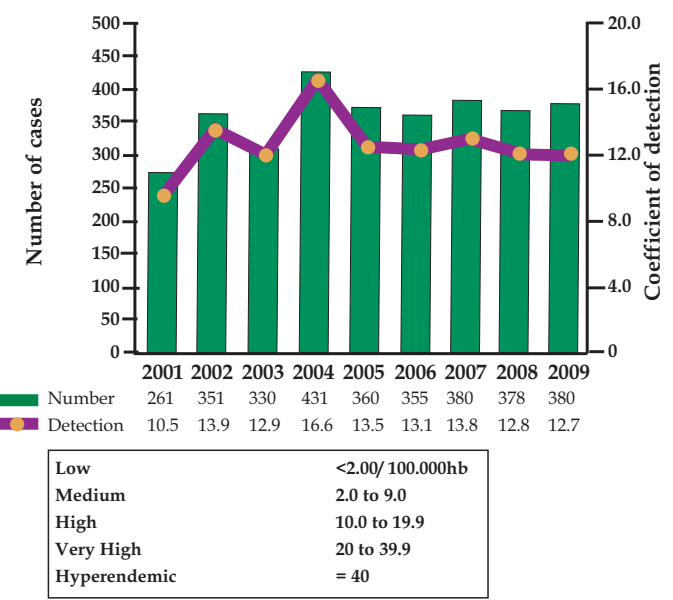

GRAPH 2: Rate of annual detection in the population of Salvador from 2001 to 2009

TABLE 2: Profile of 3,226 patients diagnosed and reported to SINAN in the period 2001-2009 in Salvador

\begin{tabular}{|c|c|c|c|c|c|c|c|c|c|c|c|c|c|c|c|c|c|c|c|c|}
\hline \multicolumn{21}{|l|}{ Variable } \\
\hline Age $<15$ Years & 22 & $7,5 \%$ & 24 & $8,3 \%$ & 41 & $14,1 \%$ & 43 & $14,8 \%$ & 35 & $12,9 \%$ & 39 & $13,5 \%$ & 43 & $14,8 \%$ & 28 & $9,6 \%$ & 15 & $5,1 \%$ & 290 & $9 \%$ \\
\hline$>15$ Years & 239 & $8,1 \%$ & 327 & $11,1 \%$ & 289 & $9,8 \%$ & 388 & $13,2 \%$ & 325 & $11,6 \%$ & 316 & $10,7 \%$ & 337 & $11,5 \%$ & 350 & $11,9 \%$ & 365 & $12,4 \%$ & 2.936 & $1 \%$ \\
\hline Masculine & 116 & $44,4 \%$ & 154 & $43,9 \%$ & 174 & $52,7 \%$ & 207 & $48 \%$ & 176 & $48,9 \%$ & 171 & $48,2 \%$ & 181 & $47,6 \%$ & 199 & $52,6 \%$ & 186 & $48,9 \%$ & 1.564 & $48,5 \%$ \\
\hline Feminine & 145 & $55,5 \%$ & 197 & $56,1 \%$ & 156 & $47,3 \%$ & 224 & $52 \%$ & 184 & $51,1 \%$ & 184 & $51,8 \%$ & 198 & $52,1 \%$ & 179 & $47,4 \%$ & 194 & $51,1 \%$ & 1.661 & $51,5 \%$ \\
\hline Unknown & 0 & & 0 & & 0 & & 0 & & 0 & & 0 & & 1 & $0,3 \%$ & 0 & & 0 & & 1 & - \\
\hline \multicolumn{21}{|c|}{ Operational classification } \\
\hline Paucibacillary & 127 & $48,7 \%$ & 189 & $53,9 \%$ & 206 & $62,4 \%$ & 264 & $61,2 \%$ & 196 & $54,4 \%$ & 171 & $48,2 \%$ & 188 & $49,5 \%$ & 163 & $43,1 \%$ & 163 & $42,9 \%$ & 1.667 & $51,7 \%$ \\
\hline Multibacillary & 134 & $51,3 \%$ & 158 & $45 \%$ & 123 & $37,3 \%$ & 164 & $38,0 \%$ & 163 & $45,3 \%$ & 183 & $51,5 \%$ & 193 & $50,8 \%$ & 216 & $57,1 \%$ & 201 & $52,9 \%$ & 1.535 & $47,6 \%$ \\
\hline Unknown & 0 & & 4 & $1,1 \%$ & 1 & $0,3 \%$ & 3 & $0,7 \%$ & 1 & $0,3 \%$ & 1 & $0,3 \%$ & 0 & & 0 & & 1 & $0,3 \%$ & 11 & $0,7 \%$ \\
\hline \multicolumn{21}{|l|}{ Clinical form } \\
\hline Indeterminate & 30 & $11,5 \%$ & 70 & $19,9 \%$ & 86 & $26 \%$ & 112 & $26 \%$ & 78 & $21,7 \%$ & 50 & $14,1 \%$ & 48 & $12,6 \%$ & 33 & $8,7 \%$ & 38 & $10 \%$ & 545 & $16,9 \%$ \\
\hline Tuberculoid & 96 & $36,8 \%$ & 114 & $32,5 \%$ & 116 & $35,2 \%$ & 141 & $32,7 \%$ & 103 & $28,6 \%$ & 104 & $29,3 \%$ & 115 & $30,3 \%$ & 130 & $34,4 \%$ & 119 & $31,3 \%$ & 1.038 & $32,2 \%$ \\
\hline Dimorphic & 63 & $24,1 \%$ & 73 & $20,8 \%$ & 61 & $18,5 \%$ & 102 & $23,7 \%$ & 104 & $28,9 \%$ & 130 & $36,6 \%$ & 113 & $29,7 \%$ & 141 & $37,3 \%$ & 141 & $37,1 \%$ & 901 & $28,8 \%$ \\
\hline Virchowian & 72 & $27,6 \%$ & 87 & $24,8 \%$ & 62 & $18,8 \%$ & 66 & $15,3 \%$ & 53 & $14,7 \%$ & 50 & $14,1 \%$ & 50 & $13,2 \%$ & 62 & $16,4 \%$ & 64 & $16,8 \%$ & 566 & $17,5 \%$ \\
\hline Unclassified/ & 0 & & 7 & $2.0 \%$ & 5 & $1,5 \%$ & 10 & $2,3 \%$ & 22 & $6,1 \%$ & 21 & $5,9 \%$ & 54 & $14,2 \%$ & 12 & $3,1 \%$ & 18 & $4,7 \%$ & 149 & $4,60 \%$ \\
\hline \multicolumn{21}{|c|}{ Unknown/No input } \\
\hline Total & 261 & $8 \%$ & 351 & $10,9 \%$ & 330 & $10,2 \%$ & 431 & $13,4 \%$ & 360 & $11,2 \%$ & 355 & $11 \%$ & 380 & $11,8 \%$ & 378 & $11,7 \%$ & 380 & $11,8 \%$ & 3.226 & \\
\hline
\end{tabular}


TABLE 3: Patients with any degree of disability and percentage of cases with grade 2 disabilities at diagnosis, reported to SINAN in the period 2001-2009 in Salvador*

\begin{tabular}{|c|c|c|c|c|c|c|c|c|c|c|c|c|c|c|c|c|c|c|c|c|}
\hline $\begin{array}{l}\text { Degree of physical } \\
\text { disability at diagnosis }\end{array}$ & \multicolumn{2}{|l|}{2001} & \multicolumn{2}{|l|}{2002} & \multicolumn{2}{|l|}{2003} & \multicolumn{2}{|l|}{2004} & \multicolumn{2}{|l|}{2005} & \multicolumn{2}{|l|}{2006} & \multicolumn{2}{|c|}{2007} & \multicolumn{2}{|l|}{2008} & \multicolumn{2}{|l|}{2009} & \multicolumn{2}{|c|}{ TOTAL } \\
\hline Grade 0 & 180 & $5,94 \%$ & 239 & $7,89 \%$ & 261 & $8,62 \%$ & 377 & $12,45 \%$ & 298 & $9,84 \%$ & 305 & $10,7 \%$ & 256 & $8,46 \%$ & 291 & $9,61 \%$ & 284 & $9,38 \%$ & 2.491 & $82,89 \%$ \\
\hline Grade 1 & 37 & $1,22 \%$ & 44 & $1,45 \%$ & 42 & $1,38 \%$ & 35 & $1,15 \%$ & 43 & $1,42 \%$ & 27 & $0,89 \%$ & 86 & $2,84 \%$ & 43 & $1,42 \%$ & 53 & $1,75 \%$ & 410 & $13,52 \%$ \\
\hline Grade 2 & 11 & $0,36 \%$ & 7 & $0,23 \%$ & 9 & $0,29 \%$ & 12 & $0,39 \%$ & 8 & $0,26 \%$ & 15 & $0,49 \%$ & 22 & $0,72 \%$ & 22 & $0,72 \%$ & 19 & $0,62 \%$ & 125 & $4,08 \%$ \\
\hline $\begin{array}{l}\text { Percentage with } \\
\text { disabilities Grade } 2\end{array}$ & $4.8 \%$ & & $2.4 \%$ & & $2.9 \%$ & & $2.8 \%$ & & $2.3 \%$ & & $4.3 \%$ & & $6.0 \%$ & & $6.2 \%$ & & $5.3 \%$ & & 3.026 & \\
\hline
\end{tabular}

\begin{tabular}{|llll}
\hline Low $<5 \%$ & Medium & 5 a $9 \%$ & High $\geq 10 \%$ \\
\hline
\end{tabular}
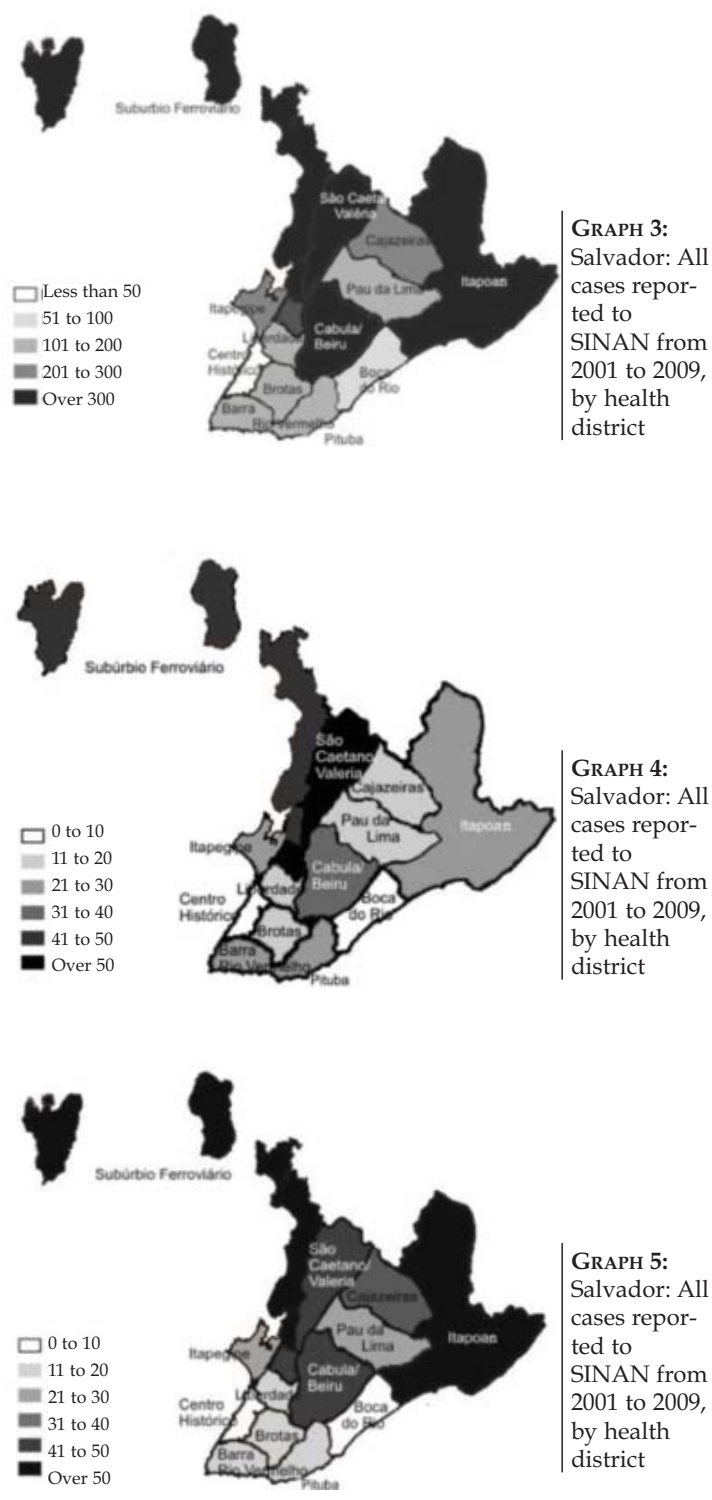

GraPH 5:

Salvador: All cases reported to SINAN from 2001 to 2009 , by health district

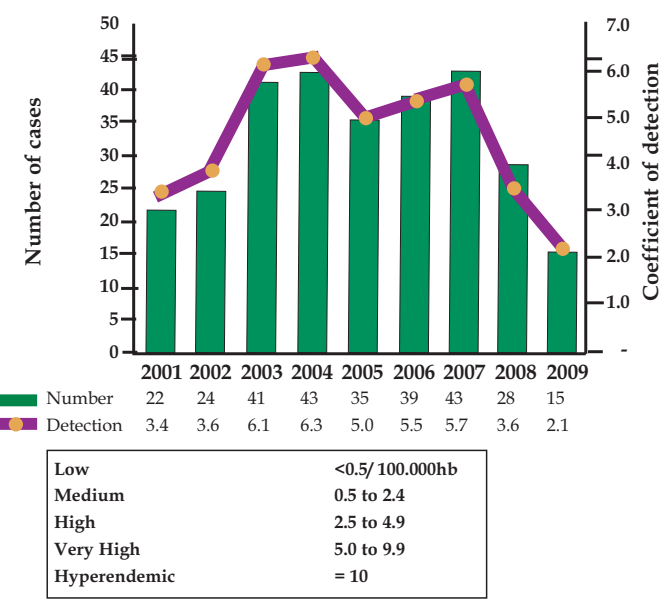

GrAPH 6: Rate of annual detection in children under 15 years old in Salvador from 2001 to 2009

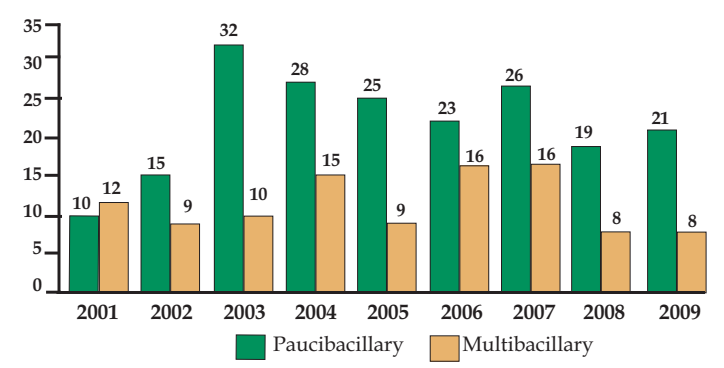

GRAPH 7: Number of paucibacillary and multibacillary patients under 15 years old in Salvador from 2001 to 2009

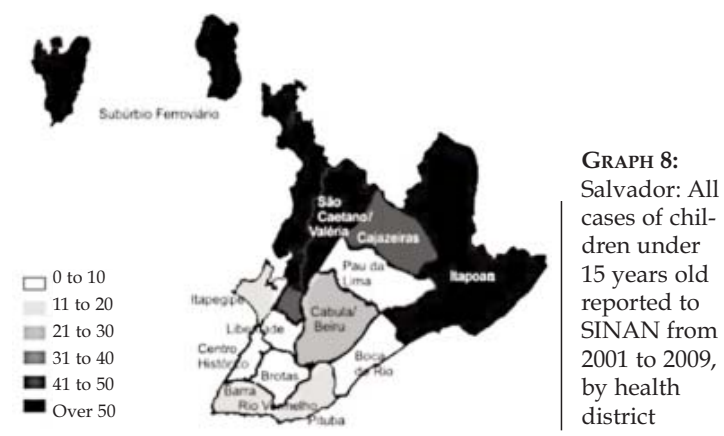


index because of a national campaign launched by the Ministry of Health ("Let's remove this spot from Brazil!") mobilizing several states with information about the disease and how to identify it.

The percentage of women was larger in this study $(51.5 \%)$. This is not similar to the findings of other studies,,$^{25,27}$ however it can be explained by the currently experienced cultural and sociological changes, which generate greater exposure for women, thus an increase in the number of diagnosed women is expected on the years to come..$^{26,32}$

The occurrence of a larger number of paucibacillary cases, mainly of the tuberculoid form in the general population, is an indicator of the expansion of the disease, implying larger amounts of circulating Mycobacterium leprae, leading to infection and illness in immunocompetent persons. ${ }^{32,10}$

The analysis of the health district cartograms agrees with literature data regarding the population more likely to develop the disease. The most financially stricken health districts were also the source of the majority of notifications on SINAN, influenced by aspects such as wealth, education and longevity; moreover, these data have identified the health districts which require priority health actions. ${ }^{6,26}$

The total number of leprosy cases found in children under 15 years is considerably lower than in the general population, 209 patients $(9 \%)$, demonstrating the slow incubation character of Mycobacterium leprae, in agreement with data from other studies. ${ }^{27,10}$

The same factors that influenced the detection rate in the general population, affected the population under 15 years (which varied from medium to very high). It is very important to highlight this index, because since 2007, it was chosen as the new indicator for leprosy elimination, instead of the prevalence index.,32 Through this indicator one can track the trends of growth or decline of the disease, since if there are children under 15 years affected, that would indicate an early contact with a bacillus carrier, probably within home, where the chances of contracting Hansen's disease would be thrice the normal.

In younger than 15 years the predominant clinical form was the paucibacillary (tuberculoid and indeterminate), a finding that is in agreement with the literature, as the indeterminate form is expected to be the initial presentation of the disease due to the long incubation period of Mycobacterium leprae. The available data were not classified by clinical form, so we can only assume, in general, that the diagnosis in people under 15 years old is being done early, thanks to the work promoted in schools. ${ }^{25,27}$

Of all the patients, $17.6 \%$ had some degree of disability at the moment of examination, reflecting an early diagnosis. This result is similar to the ones achieved in studies that were based on secondary data, but it differs from data obtained from studies in which the examination was made by the researchers themselves, suggesting a lack of skilled professionals to perform the exams. ${ }^{26}$

The proportion of grade 2 disabilities is an indicator of the quality of care; in recent years in Salvador the achieved level was average. ${ }^{10,27}$ That suggests deterioration in medical care provided to these patients and implies that there should be greater attention and investment in treatments with multidisciplinary teams, in order to prevent a decrease in the quality of life of the patients. Also, it is important to effectively reinstate treated patients into society and since most of those affected belong to the economically active population, rehabilitate them to return to work, thereby lowering the costs of inactive patients to the State, for it is known that the most common deformities of leprosy include paralysis of the hands, loss of fingers and even blindness. ${ }^{27,26}$

Prevalence rate, widely used in researches, was not useful in this kind of epidemiological study because the numbers do not seem consistent with reality, since they include patients that were detected, cured and even those who abandoned treatment. ${ }^{3,32}$

\section{CONCLUSION}

Based on the results obtained in this study, it can be inferred that the detection rate of leprosy in Salvador remained at high levels of endemicity in the general population, ranging from medium to very high in children under 15 years. There was a predominance of the disease in the adult population (over 15 years), in the female gender, and of paucibacillary forms, particularly tuberculoid, indication the expansion of the disease. It can also be inferred that grade 2 disability was more present at levels considered low to medium at the time diagnosis.

The health districts, which had the greater number of notifications in the general population and in children under 15 years old, were also the most populous and the ones with lowest socioeconomic status.

One of the main limitations of this study is the fact that all collected data was secondary to an operational system that depends on the healthcare professionals' input and is subject to public health policies. We emphasize the importance of further studies in this area that may expand the knowledge and encourage more effective and specific health actions in the city.

We conclude that there is a need for active surveillance to achieve early detection of hanseniasis, to prevent possible sequelae and that public health actions in the most affected areas should be reinforced. $\square$ 


\section{REFERENCES}

1. Departamento de Ciência e Tecnologia, Secretaria de Ciência, Tecnologia e Insumos Estratégicos, Ministério da Saúde. Doenças negligenciadas: estratégias do Ministério da Saúde (Neglected diseases: strategies of the Ministry of Health). Rev Saude Publica 2010;44:200-2.

2. Albuquerque MFPM, Morais HMM, Ximenes R. A expansão da hanseníase no nordeste brasileiro (The increase of leprosy in the Northeastern region of Brazil). Rev. Saude Publica 1989;23:107-16.

3. Penna ML, Penna G0. Trend of case detection and leprosy elimination in Brazil Trop Med Int Health. 2007;12:647-50.

4. Saude.ba.gov [página na Internet]. Sesab mobiliza municípios e Dires para o dia mundial de luta contra a hanseníase (SESAB mobilizes cities and DIRs for World Day of fight against leprosy) 2010 [acesso 20 Fev 2010]. Disponível em: http://www1.saude.ba.gov.br/noticias/noticia.asp?NOTICIA=8351

5. Santos AS, Castro DS, Falqueto $A$. Fatores de risco para transmissão da Hanseníase (Risk factors for Leprosy transmission). Rev Bras Enferm. 2008:61:738-43.

6. Souza WV, Barcellos CC, Cruz OC, Albuquerque MFM, et al. Aplicação de modelo bayesiano empírico na análise espacial da ocorrência de hanseníase (Empirical bayesian model applied to the spatial analysis of leprosy occurrence). Rev Saúde Pública. 2001;35:474-80.

7. Araújo MG. Hanseníase no Brasil (Leprosy in Brazil). Rev Soc Bras Med Trop 2003:36:373-82.

8. Rodrigues-Júnior AL, do O VT, Motti VG. Spatial and temporal study of leprosy in the state of São Paulo (Southeastern Brazil), 2004-2006. Rev Saude Publica. 2008;42:1012-20.

9. de Matos HJ, Duppre N, Alvim MF, MachadoVieira LM, Sarno EN, Struchiner CJ. Leprosy epidemiology in a cohort of household contacts in Rio de Janeiro (19871991). Cad Saude Publica 1999;15:533-542.

10. Ferreira SM, Ignotti E, Gamba MA. Clinical and laboratory characteristics in the retreatment of leprosy relapse. Rev Bras Epidemiol. 2012;15:573-81.

11. Goulart IM, Penna GO, Cunha G. Immunopathology of leprosy: the complexity of the mechanisms of host immune response to Mycobacterium leprae. Rev Soc Bras Med Trop. 2002;35:365-75.

12. Barbosa Júnior Ade A, Jambeiro J, Cirqueira JS, Silva TC. Retrospective histopathological classification of 1,108 skin biopsies from patients clinically suspected of having leprosy from Bahia, Northeast Brazil. Rev Soc Bras Med Trop. 1998;31:533-7.

13. SOUZA CS. Hanseníase: formas clínicas e diagnóstico diferencial (Leprosy: clinical forms and differential diagnosis). Medicina (Ribeirão Preto). 1997;30: 325-34.

14. Brasil. Ministério da Saúde. Secretaria de Vigilância em Saúde, Secretaria de Atenção à Saúde. Portaria $n^{0}$. 125/SVS-SAS, de 26 de março de 2009. Define ações de controle da hanseníase (Ordinance No. 125/SVS-SAS of March 26, 2009. Defines actions to control leprosy). Diário Oficial Da União 27 março de 2009.

15. Grossi MA, Leboeuf MA, Andrade AR, Lyon S, Antunes CM, Bührer-Sékula S. A influência do teste sorológico ML Flow na classificação da hanseníase (The influence of ML Flow test in leprosy classification). Rev Soc Bras Med Trop. 2008;41:34-8

16. Bakirtzief Z. Obstacles to compliance with treatment for Hansen's disease. Cad Saude Publica. 1996;12:497-505.

17. Barata RA, Briceña-Leon R. Doenças endêmicas: abordagens socioculturais e comportamentais (Endemic diseases: socio-cultural and behavioral approaches). 20. ed. Rio de Janeiro: Fiocruz; 2000. p.101-13; 199 - 213.

18. Jornal do Movimento de Reintegração das Pessoas atingidas pela Hanseníase MORHAN (Journal of the Leprosy patients' reintegration movement). 2006;43: 4-5.

19. Baialardi KS. O Estigma da Hanseníase: Relato de uma Experiência em Grupo com Pessoas Portadoras (The Hansen's Disease Stigma: an Account of a Group Experience with Hansen's Disease Patients). Hansen Int. 2007;32:27-3.

20. Savassi LCM. Hanseníase: políticas públicas e qualidade de vida de pacientes e seus cuidadores [dissertação] - (Leprosy: public politics and quality of life for patients and healthcare providers - dissertation). Belo Horizonte (MG): Fundação Oswaldo Cruz; 2010.

21. Bíblia Sagrada [página na internet]. Levítico 13. Almeida JF de, tradutor. [acesso 7 Set. 2010]. Disponível em: http://biblia.com.br/joao-ferreira-almeida-corrigidarevisada-fiel/levitico/lv-capitulo-13

22. Baruffa G. Let's call it hanseniasis. Hansen Int. 1979;4:113-5.
23. Kerr-Pontes LR, Montenegro AC, Barreto ML, Werneck GL, Feldmeier H. Inequality and leprosy in Northeast Brazil: an ecological study. Int J Epidemiol. 2004;33:262-9.

24. Penna GO, Pinheiro AM, Nogueira LS, Carvalho LR, Oliveira MB, Carreiro VP. Clinical and epidemiological study of leprosy cases in the University Hospital of Brasília: 20 years - 1985 to 2005. Rev Soc Bras Med Trop. 2008;41:575-80.

25. Hinrichsen SL. Epidemiologic aspects of leprosy in the city of Recife, Pernambuco state, 2002. An Bras Dermatol 2004;79:413-21.

26. Aquino DM, Caldas Ade J, da Silva AA, Costa JM. Profile of leprosy patients in a hyperendemic area of Amazonian Maranhão, Brazil. Rev Soc Bras Med Trop. 2003;36:57-64

27. Imbiriba EB, Hurtado-Guerrero JC, Garnelo L, Levino A, Cunha Mda G, Pedrosa V. Epidemiological profile of leprosy in children under 15 in Manaus (Northern Brazil), 1998-2005. Rev Saude Publica. 2008:42:1021-6

28. Nogueira W, Marzliak MLC. Perspectivas da eliminação da hanseníase no estado de São Paulo e no Brasil (Perspective for elimination of leprosy in the state of Sao Paulo and in Brazil). Medicina (Ribeirão Preto). 1997:30:364-70.

29. The International Leprosy Association (ILA). Relatório do Fórum Técnico da ILA; 2002 fev. 25-28; Paris. Franç. The International Leprosy Association; 2002.

30. Silva P. Farmacologia (Pharmacology). 7 ed. Rio de Janeiro: Guanabara Koogan; 2006. p.1050-1.

31. Soares CGM. Hanseníase no estado do Pará: perfil epidemiológico da população que demanda internação por reações hansênicas [dissertação] (Leprosy in the State of Pará: epidemiological profile of the population that requires admission due to hanseniasis reactions - dissertation). Belém (PA): Fundação Oswaldo Cruz; 2001.

32. Figueiredo IA, da Silva AA. Increase in leprosy detection rates in São Luís, Maranhão, Brazil, from 1993 to 1998: is the endemic expanding? Cad Saude Publica. 2003;19:439-45.

33. Opromolla PA, Dalben I, Cardim M. Geo statistical analysis of leprosy cases in the State of São Paulo, 1991-2002. Rev Saude Publica. 2006;40:907-13.

34. Saude.ba.gov [página na Internet]. Hospital Dom Rodrigo de Menezes comemora 59 anos de fundação (Dom Rodrigo de Menezes Hospital celebrates 59 years), 2010 [acesso 7 Set. 2010]. Disponível em: http://www.saude.ba.gov.br/noticias/ noticia.asp?NOTICIA $=3884$

35. Datasus.gov [página na Internet]. Taxa de detecção de hanseníase em Brasil e Grandes Regiões, 1994,1996 e 1998 [acesso 3 Abr. 2009] (Leprosy detection rates in Brazil e larger regions, 1994, 1996 and 1998). Disponível em: http://tabnet.datasus.gov.br/cgi/idb2000/fqd03.htm

36. Santos AA, Mota CG, Salati E, Nascimento EA, Castro Júnior E, Bruni RRG, et al Brasil: 0 Livro dos 500 anos. São Paulo: Abril; 2000.

37. Ibge.gov [página na Internet]. IBGE divulga as estimativas populacionais dos municípios, 2009 [acesso 29 0ut. 2010] (IBGE publishes population estimates by city for 2009). Disponível em: http://www.ibge.gov.br/home/presidencia/noticias/noticia_visualiza.php?id_noticia $=1435 \&$ id_pagina $=1$.

How to cite this article: Moreira SC, Batos CJC, Tawil L. Epidemiological situation of leprosy in Salvador from 2001 to 2009. An Bras Dermatol. 2014;89(1):107-17. 